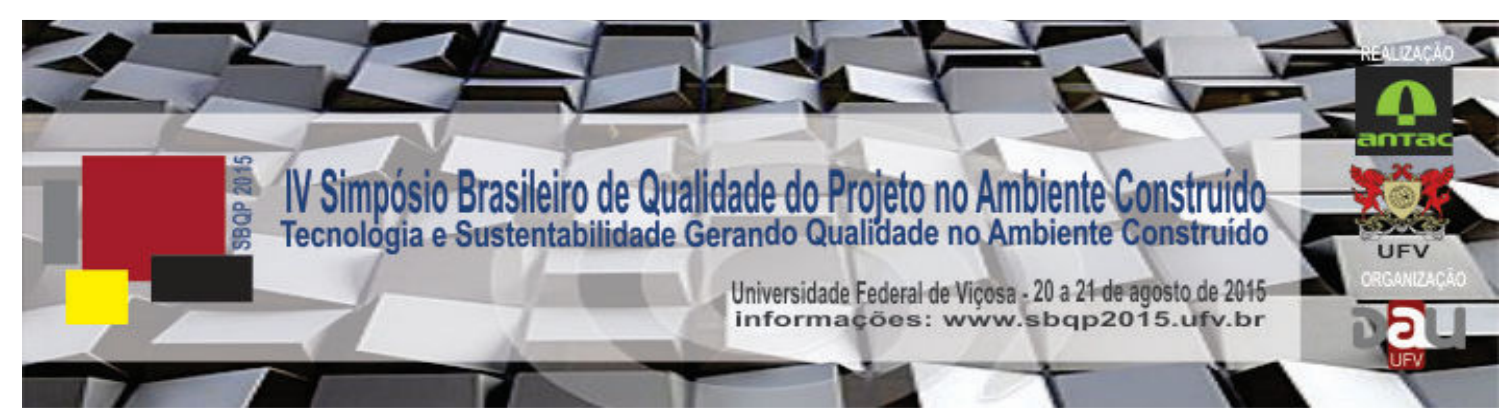

\title{
UMA ESTRATÉGIA PROJETUAL DE JOAQUIM GUEDES APLICADA NA PROPOSTA PARA O TEATRO DE LONDRINA ${ }^{1}$
}

\author{
SCHIMIDT, Rafael; \\ Universidade Presbiteriana Mackenzie, rafschimidt@gmail.com
}

\begin{abstract}
RESUMO
O objetivo desse ensaio é apresentar uma análise da estratégia projetual desenvolvida por Joaquim Guedes conhecida por Teoria dos Sistemas e Subsistemas de espaço. O objeto desse estudo são os diagramas lineares usados no projeto proposto para o Concurso Público do Teatro Municipal de Londrina. Para analisar esse projeto aplicouse o método proposto por Richard Foqué para produção de estudos de caso. Esse ensaio contribui para o esclarecimento da criação da forma no processo projetual de Guedes.
\end{abstract}

Palavras-chave: Projeto, Processo, Diagramas.

\begin{abstract}
The purpose of this essay is to present an analysis of the design strategy known as Space Systems and Subsystems Theory, developed by Joaquim Guedes. The object of this study are the linear diagrams used in the project proposed for the Public Competition for the Londrina Municipal Theatre. To analyze this project we applied the method for the production of case studies, proposed by Richard Foqué. This paper contributes to clarify the form creation in Guedes design process.
\end{abstract}

Keywords: Project, Process, Diagrams.

\section{INTRODUÇÃO}

Este ensaio é derivado de um estudo de caso desenvolvido como um instrumento de análise do processo de projeto aplicado pelo arquiteto Joaquim Guedes e equipel, entre 2006 e 2007, para o Concurso Público Nacional de anteprojeto de arquitetura para o Teatro Municipal da cidade de Londrina, no Paraná. Sua proposta é analisar a estratégia projetual dos Sistemas e Subsistemas de espaço com o uso de diagramas lineares.

\footnotetext{
${ }^{1}$ Trabalho apresentado no IV SBQP 2015. Universidade Federal de Viçosa. Disponível em: doi> http://dx.doi.org/10.18540/2176-4549.6041
} 


\title{
2 FUNDAMENTAÇÃO
}

Dentre as diversas estratégias projetuais aplicadas, existe alguma métrica ou parâmetro específico que defina um projeto plausível e adequado para cada contexto distinto? E como proceder para investigar essas dúvidas?

Um caso exemplar é do arquiteto Joaquim Guedes que sistematizou sua estratégia de projeto com o uso de diagramas ao longo dos anos, aplicandoa didaticamente em alguns de seus últimos projetos desenvolvidos para concursos públicos. Consistia na análise e posteriormente na síntese de grandes programas de necessidades à luz de Sistemas e Subsistemas de espaço trabalhados de maneira diagramática para que a forma do objeto arquitetônico derivasse desse procedimento. A proposta para o Teatro de Londrina $^{2}$ (não publicada anteriormente) é um dos casos em que Guedes aplicou essa estratégia projetual e disso deriva o interesse em analisar tal projeto.

Valter Caldana compreende esse processo de projeto desenvolvido por Guedes conforme uma Teoria, e sintetiza:

\begin{abstract}
Batizada de teoria dos Sistemas e Subsistemas, indica com clareza a necessidade de um profundo conhecimento do lugar e do programa pretendido pelo cliente como premissas para a elaboração do projeto. [...] Guedes propunha uma intensa exploração do lugar e dos elementos programáticos através do aprofundamento do conhecimento destes pelo arquiteto. É a partir desse conhecimento que o arquiteto toma contato com a essência do problema a ele colocado e passa a ter condições de formular a resposta (CALDANA, 2005, p. 150).
\end{abstract}

A relevância científica e social dessa pesquisa consiste na investigação dos procedimentos projetuais do arquiteto Joaquim Guedes, além da contribuição para o ensino da teoria e prática do projetar em arquitetura.

\section{MÉTODO}

O método de análise aplicado no estudo de caso foi o proposto por Richard Foqué e é baseado no modelo que ele chama de Tipo 1 ou Produto, Contexto e Processo. Esse tipo de análise foi usado de maneira parcial no projeto para $o$ Teatro de Londrina, apresentando-se aqui apenas o item de Processo. Para Foqué, "comparar informação das múltiplas partes envolvidas com a mesma história transforma interpretações subjetivas e verdades acreditadas em fatos contextuais objetivos" (FOQUÉ, 2010, p. 203, tradução nossa).

\section{RESULTADOS E DISCUSSÃO}

A área de intervenção proposta localizava-se na região central da cidade a cerca de 400,00 m a sudeste do Terminal Rodoviário de Londrina (Figura 1). 
Figura 1: Vista aérea da área destinada ao Teatro de Londrina, com o Bosque do Marco Zero à direita e, ao fundo, a rodoviária da cidade.

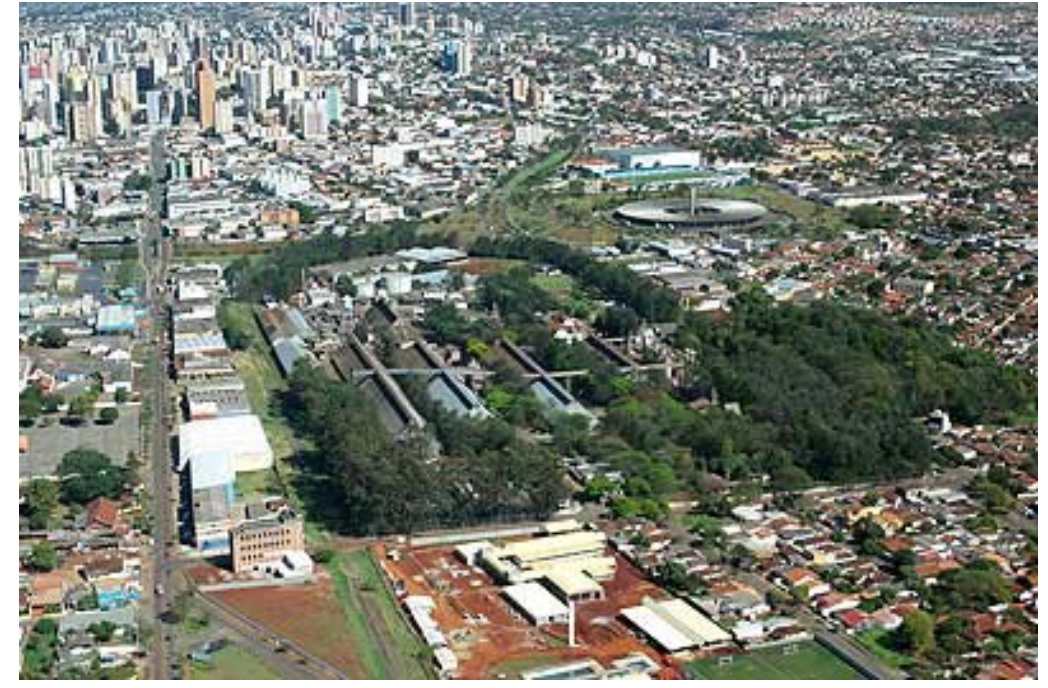

Fonte: Base de Dados do concurso.

Tal lote possuía 19.893,94 $\mathrm{m}^{2}$ e tinha privilegiado destaque visual no contexto urbano do local, tanto por sua implantação quanto por suas cotas de nível, situadas acima de todo o conjunto da superquadra, chamada de empreendimento Condomínio Marco Zero (Figura 2).

Figura 2: Desenho de implantação com dados planos e altimétricos do terreno em destaque (sem escala).

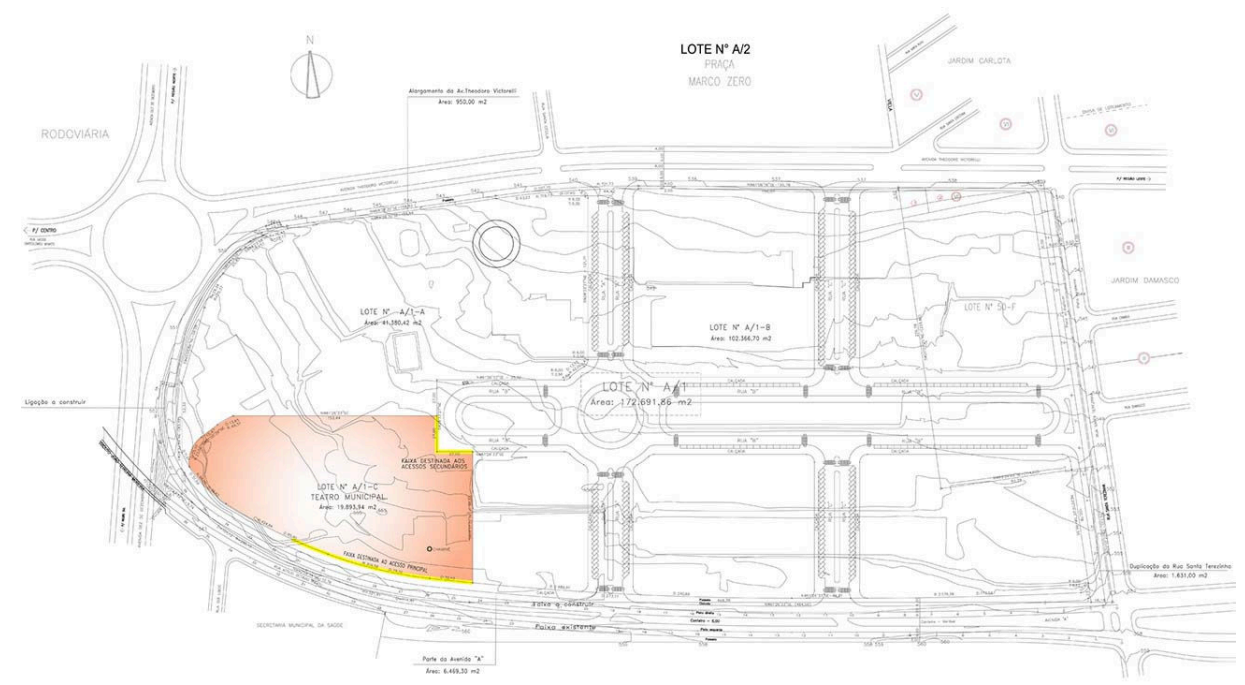

Fonte: Base de Dados do concurso.

Verificou-se em visita ao local, que o terreno encontrava-se praticamente desocupado, apresentando apenas algumas ruínas de pequenas construções e uma antiga chaminé (Figura 3): "O volume de chaminé de tijolos aparentes, situado no terreno destinado ao Teatro Municipal, poderá ser preservado e valorizado no projeto de paisagismo, a critério do projetista" (TERMO DE REFERÊNCIA, 2006, p. 15). 
Figura 3: Vista do terreno desde o interior do loteamento.

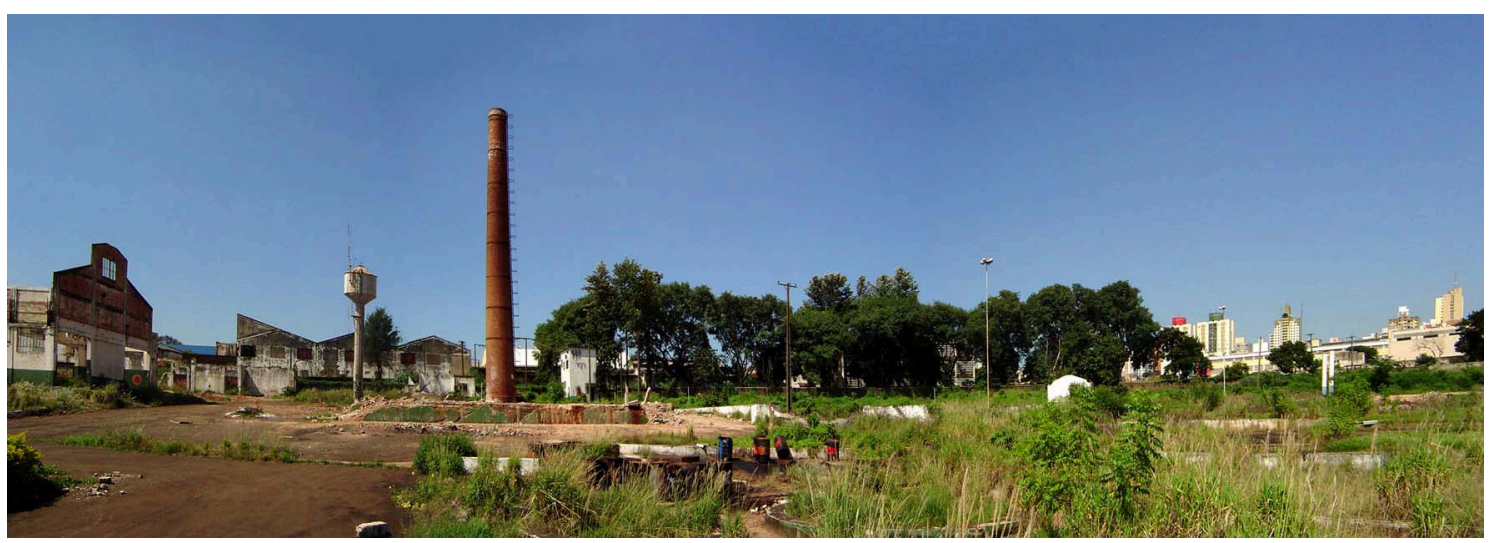

Fonte: Acervo do autor.

Com relação aos espaços solicitados no Programa de Necessidades, percebeu-se de início que em vários desses espaços não estavam indicadas as áreas necessárias para as atividades. Para conhecer a dimensão real da área de construção foi necessário, primeiramente, completar as lacunas no Programa.

Também, durante essa organização, foi sugerida uma primeira possível divisão dos espaços em 6 grandes Subsistemas (coloridos pelo autor) com características comuns de funcionamento: Sala 1, Sala 2, Sala de Uso Múltiplo, Setor Didático, Setor Administrativo e Áreas Técnicas (Tabela 1). 


\section{Tabela 1: Divisão dos espaços em Subsistemas e revisão das áreas solicitadas pelo Programa de Necessidades (cores pelo autor).}

\begin{tabular}{|c|c|c|}
\hline \multirow[t]{12}{*}{ sala 1} & ss 1.01 & plateia \\
\hline & ss 1.02 & fosso orquestra \\
\hline & ss1.03 & palco+coxias \\
\hline & ss1.04 & porão \\
\hline & ss 1.05 & dimmers \\
\hline & ss1.06 & cabine controle: luz, som, tradução, projeção \\
\hline & ss 1.07 & camarins \\
\hline & ss1.08 & foyer salas $1+2+3$ \\
\hline & ss1.09 & wc \\
\hline & ss 1.10 & chapelaria \\
\hline & ss1.11 & divulgação + bilheteria central \\
\hline & ss1.12 & exposição \\
\hline \multicolumn{3}{|l|}{ subtotal ss1 } \\
\hline \multirow[t]{7}{*}{ sala 2} & ss2.01 & plateia \\
\hline & ss2.02 & palco+coxias \\
\hline & ss2.03 & porão \\
\hline & ss2.04 & dimmers \\
\hline & ss2.05 & cabine controle \\
\hline & ss2.06 & camarins \\
\hline & ss2.07 & wc \\
\hline \multicolumn{3}{|l|}{ subtotal ss2 } \\
\hline \multirow[t]{3}{*}{ sala de uso múltiplo } & ss3.01 & sala de uso múltiplo \\
\hline & ss3.02 & camarins \\
\hline & ss3.03 & wc \\
\hline \multicolumn{3}{|l|}{ subtotal ss3 } \\
\hline \multirow[t]{6}{*}{ setor didático } & ss4.01 & artes corporais \\
\hline & ss4.02 & artes cênicas \\
\hline & ss4.03 & artes visuais \\
\hline & ss4.04 & música \\
\hline & ss4.05 & guarda-instrumentos \\
\hline & ss4.06 & biblioteca \\
\hline \multicolumn{3}{|l|}{ subtotal ss4 } \\
\hline \multirow[t]{10}{*}{ setor administrativo } & ss5.01 & diretor \\
\hline & ss5.02 & sala funcionários (50) \\
\hline & ss5.03 & reuniões \\
\hline & ss5.04 & relações públicas \\
\hline & ss 5.05 & produção \\
\hline & ss5.06 & produção externa \\
\hline & ss5.07 & copa, coz. e vestiário \\
\hline & ss5.08 & almoxarifado \\
\hline & ss5.09 & depósito serviços \\
\hline & ss 5.10 & dep. equip. luz \\
\hline \multicolumn{3}{|l|}{ subtotal ss 5} \\
\hline \multirow[t]{16}{*}{ áreas técnicas } & ss6.01 & oficina \\
\hline & ss6.02 & figurino \\
\hline & ss6.03 & camareira \\
\hline & ss6.04 & maquinista \\
\hline & ss6.05 & eletricista \\
\hline & ss6.06 & diretor de cena \\
\hline & ss6.07 & contrarregra \\
\hline & ss6.08 & cenotécnico \\
\hline & ss6.09 & manutenção \\
\hline & ss6.10 & aderecista \\
\hline & ss6.11 & cenógrafo \\
\hline & ss6.12 & figurinista \\
\hline & ss6.13 & diretor técnico do teatro \\
\hline & ss6.14 & almoxarifado \\
\hline & ss6.15 & depósito cenários \\
\hline & ss6.16 & depósitos equip. luz \\
\hline \multicolumn{3}{|l|}{ subtotal ss 6} \\
\hline \multirow{2}{*}{$\begin{array}{l}\text { estacionamento } \\
\text { circulação }\end{array}$} & s7.01 & coberto \\
\hline & s7.02 & área de circulação: $15 \%$ \\
\hline
\end{tabular}

\begin{tabular}{|c|c|}
\hline área edital & área projeto \\
\hline 661.10 & 661.10 \\
\hline 100.00 & 100.00 \\
\hline 800.00 & 800.00 \\
\hline 800.00 & 744.00 \\
\hline 6.00 & 6.00 \\
\hline 30.00 & 44.00 \\
\hline 280.00 & 280.00 \\
\hline não consta & $1,815.00$ \\
\hline 72.00 & 72.00 \\
\hline não consta & 49.00 \\
\hline não consta & 100.00 \\
\hline 150.00 & 150.00 \\
\hline $2,899.10$ & $4,821.10$ \\
\hline $\mathrm{m} 2$ & $\mathrm{~m} 2$ \\
\hline 292.20 & 292.20 \\
\hline 375.00 & 375.00 \\
\hline 387.00 & 387.00 \\
\hline 6.00 & 6.00 \\
\hline 20.00 & 20.00 \\
\hline 160.00 & 160.00 \\
\hline não consta & 37.00 \\
\hline $1,240.20$ & $1,277.20$ \\
\hline $\mathrm{m} 2$ & $\mathrm{~m} 2$ \\
\hline 400.00 & 400.00 \\
\hline 160.00 & 160.00 \\
\hline não consta & 30.00 \\
\hline 560.00 & 590.00 \\
\hline $\mathrm{m} 2$ & $\mathrm{~m} 2$ \\
\hline 150.00 & 150.00 \\
\hline 150.00 & 150.00 \\
\hline 150.00 & 150.00 \\
\hline 150.00 & 150.00 \\
\hline 150.00 & 150.00 \\
\hline 150.00 & 274.00 \\
\hline 900.00 & $1,024.00$ \\
\hline $\mathrm{m} 2$ & $\mathrm{~m} 2$ \\
\hline não consta & 31.25 \\
\hline não consta & 220.00 \\
\hline não consta & 25.00 \\
\hline 30.00 & 30.00 \\
\hline 20.00 & 20.00 \\
\hline 20.00 & 20.00 \\
\hline 50.00 & 172.50 \\
\hline não consta & 20.00 \\
\hline não consta & 20.00 \\
\hline não consta & 20.00 \\
\hline 120.00 & 578.75 \\
\hline $\mathrm{m} 2$ & $\mathrm{~m} 2$ \\
\hline 150.00 & 150.00 \\
\hline 150.00 & 150.00 \\
\hline não consta & 15.00 \\
\hline não consta & 15.00 \\
\hline não consta & 15.00 \\
\hline não consta & 15.00 \\
\hline não consta & 15.00 \\
\hline não consta & 15.00 \\
\hline não consta & 15.00 \\
\hline não consta & 15.00 \\
\hline não consta & 15.00 \\
\hline não consta & 15.00 \\
\hline não consta & 15.00 \\
\hline não consta & 20.00 \\
\hline não consta & 20.00 \\
\hline não consta & 20.00 \\
\hline 300.00 & 525.00 \\
\hline $\mathrm{m} 2$ & $\mathrm{~m} 2$ \\
\hline \multirow[t]{2}{*}{$5,700.00$} & $5,700.00$ \\
\hline & $2,175.00$ \\
\hline $5,700.00$ & $7,875.00$ \\
\hline $\mathrm{m} 2$ & $\mathrm{~m} 2$ \\
\hline $11,719.30$ & $16,691.05$ \\
\hline
\end{tabular}

Fonte: Acervo do autor. 
Depois de completadas as áreas do Programa, o passo seguinte foi a aplicação da estratégia projetual dos chamados Diagramas Lineares. Na Figura 4, a sequência dos espaços na representação gráfica dos diagramas está diferente da sequência dos espaços apresentada anteriormente na Tabela 1, visto que foi desenvolvida uma nova organização possível dos Subsistemas: o Setor Didático foi unido com o Setor Administrativo, e as Áreas Comuns foram separadas dos Subsistemas das Salas.

\section{Figura 4: Diagramas Lineares resultantes da análise do Programa de Necessidades (aqui sem escala).}
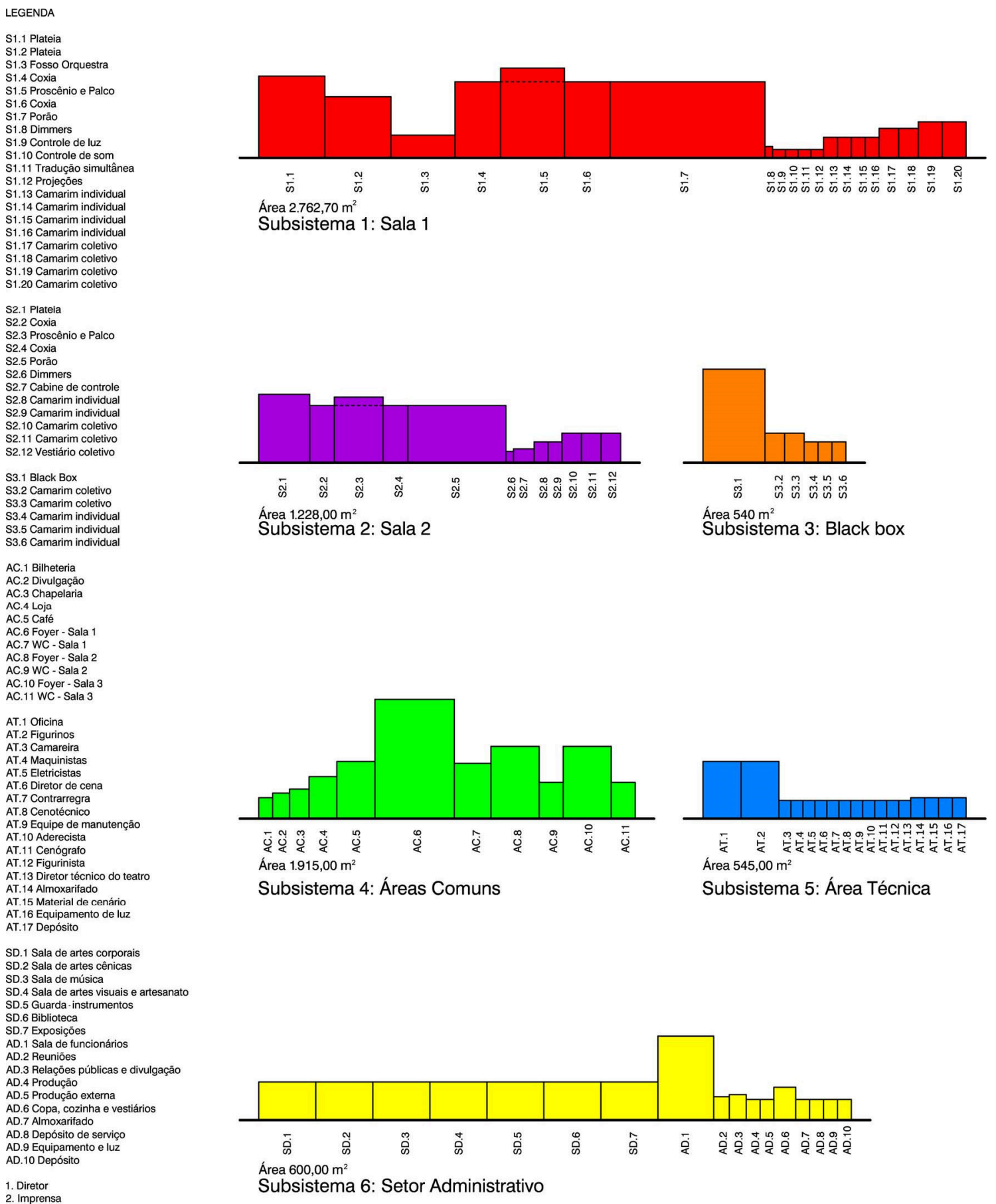

Subsistema 1: Sala 1

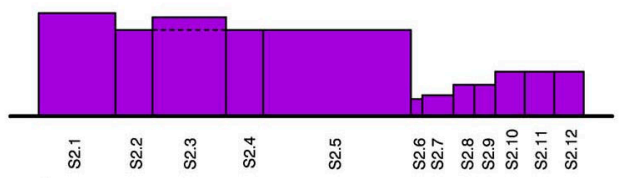

Área $1.228,00 \mathrm{~m}^{2}$ : Sala 2
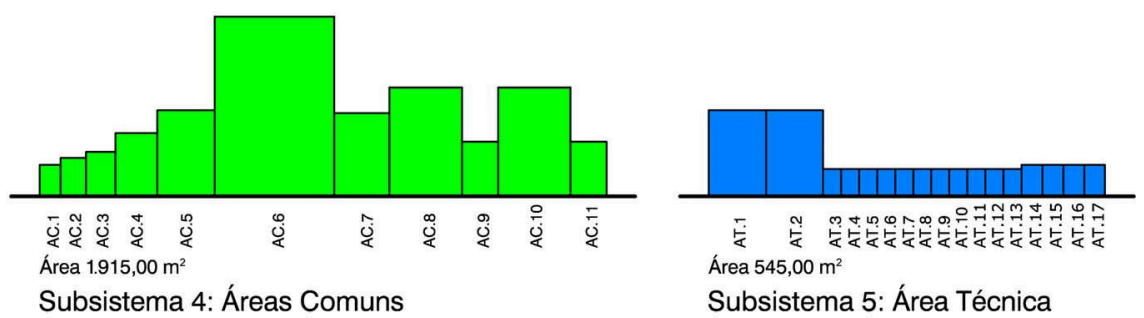

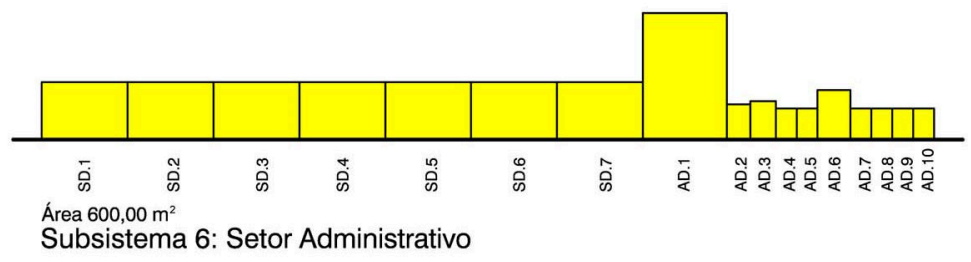

Fonte: Acervo do autor. 
Costumava-se representar, inicialmente, os diagramas das áreas de cada sala solicitada em retângulos na proporção $2 \times 3$. Porém, algumas salas requisitadas pelo Programa de Necessidades tinham dimensões explicitamente específicas devido ao uso do espaço, como por exemplo, os palcos, coxias e porões. Portanto, os diagramas desses espaços foram representados com as dimensões exigidas pelo Programa.

Outra postura usual era representar os retângulos na posição vertical com intenção de diminuir a distância total de circulação entre as salas. Todavia, vários retângulos foram representados na posição horizontal em razão das especificidades dos espaços. Por exemplo: a equipe considerou que as salas didáticas funcionariam melhor nessa posição, com a abertura no lado maior e as projeções ou quadro no lado menor.

Outra peculiaridade adotada pela equipe foi a inserção de uma Sala do Diretor e de uma Sala de Imprensa (retângulos de cor branca) no Programa solicitado pelo Termo de Referência.

Nos primeiros estudos com esses diagramas, buscou-se rearranjar os espaços entre os 6 Subsistemas de várias maneiras possíveis, com a intenção de aprimorar a organização no funcionamento de cada atividade específica em relação ao todo (Figura 5).

\section{Figura 5: Organização preliminar dos diagramas para o complexo cultural (aqui sem escala).}
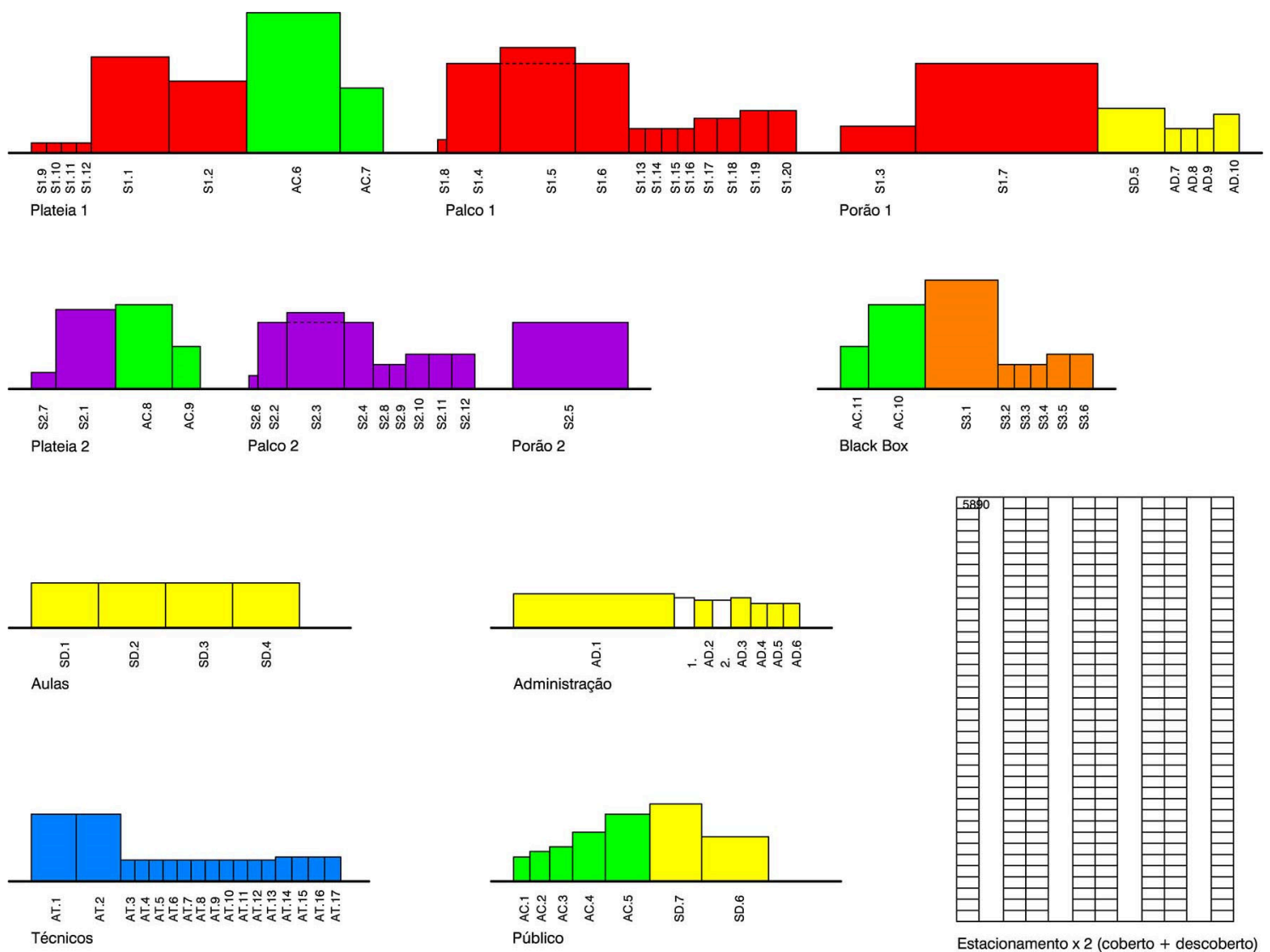

Fonte: Acervo do autor.

Depois de chegar a um arranjo satisfatório, os diagramas representando as áreas requisitadas por cada espaço foram então sintetizados em diversas 
configurações possíveis, buscando-se aperfeiçoar a relação de funcionamento entre os Subsistemas em cada conjunto (Figura 6). Os retângulos verdes na Figura 5, relativos às Áreas Comuns, não constam representados na Figura 6 porque já se imaginava que essas áreas seriam 0 elemento de conexão entre os Subsistemas.

Figura 6: Organização e cortes possíveis dos diagramas para cada subsistema específico (aqui sem escala).
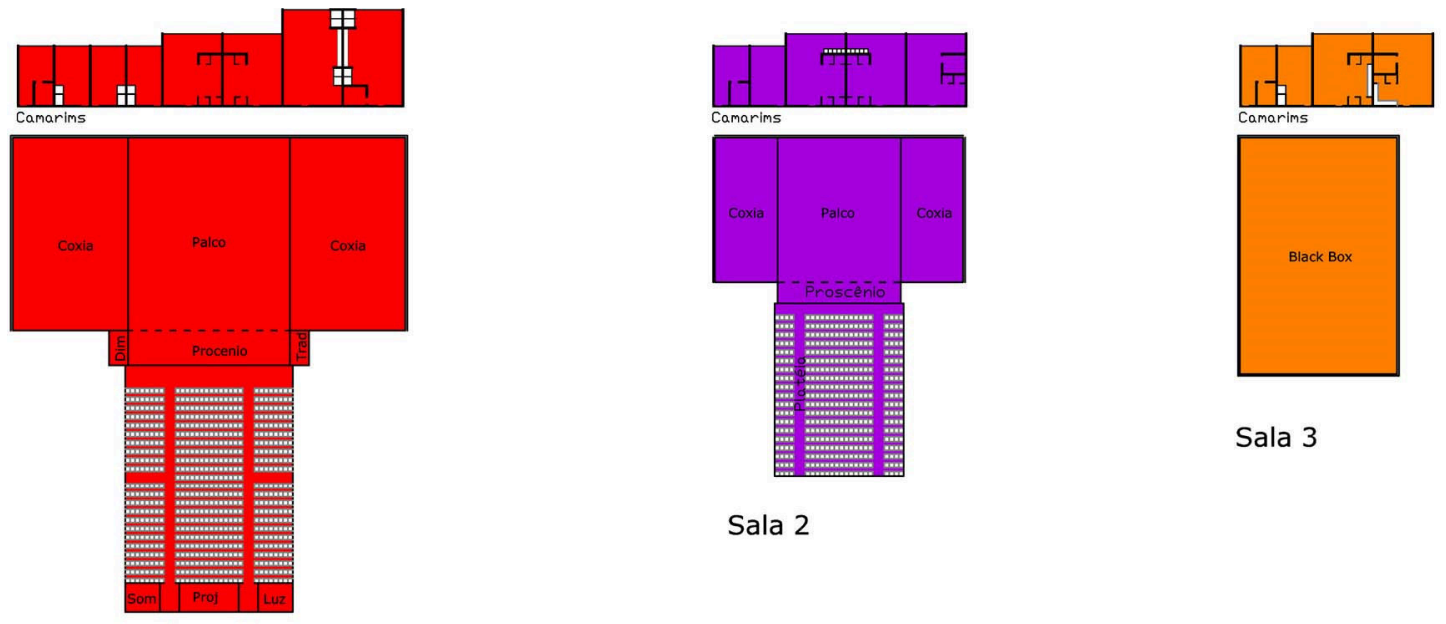

Sala 3

Sala 2

Sala 1
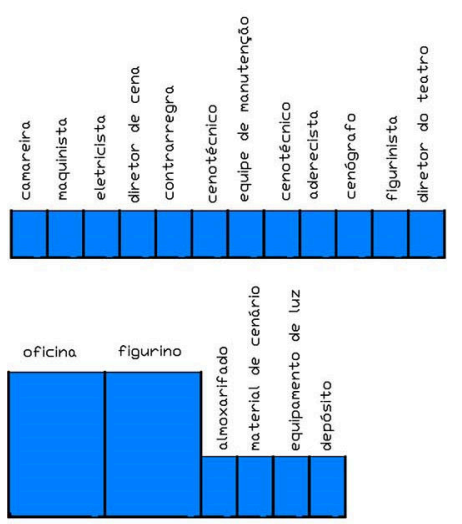

Area Técnica

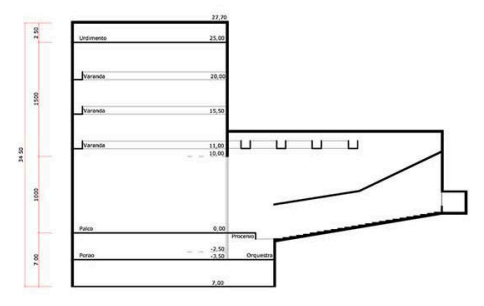

Sala 1

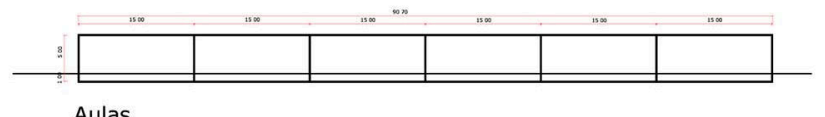

Aulas

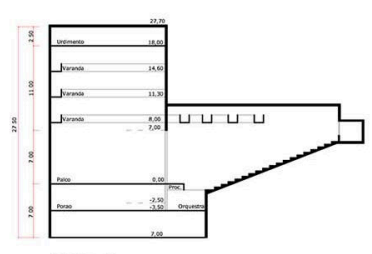

Sala 2

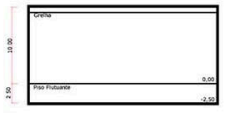

Sala 3

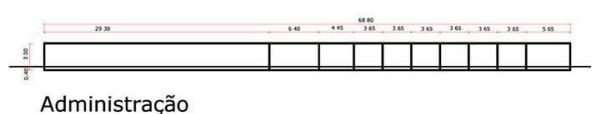

Fonte: Acervo do autor. 
Com alguns subsistemas previamente elaborados, partiu-se para o estudo das possibilidades de implantação. Inicialmente, pensou-se na distribuição das salas de apresentação e áreas técnicas no terreno, levando em consideração a permanência do volume da chaminé pré-existente.

Na fachada sul-sudoeste, para os foyers e áreas comuns, criou-se um sistema de proteção especial que fazia mais do que sombrear o grande salão. A proposta das placas metálicas verticais giratórias, sustentadas por mastros fixos pivotantes, funcionava também como elemento escultórico marcando a fachada de acesso principal.

Na fachada norte, para os camarins e áreas administrativas, foi proposto um sistema de placas horizontais e verticais nas janelas. Na fachada sul, para as salas didáticas, a proposta de placas apenas verticais resolveria plenamente o problema de insolação. Na fachada leste, para a biblioteca, exposições, loja e bilheteria, o uso de placas apenas horizontais atenuaria parcialmente a insolação, sombreando os ambientes internos a partir da metade da manhã (Figura 7).

Figura 7: Volumetria da proposta final.

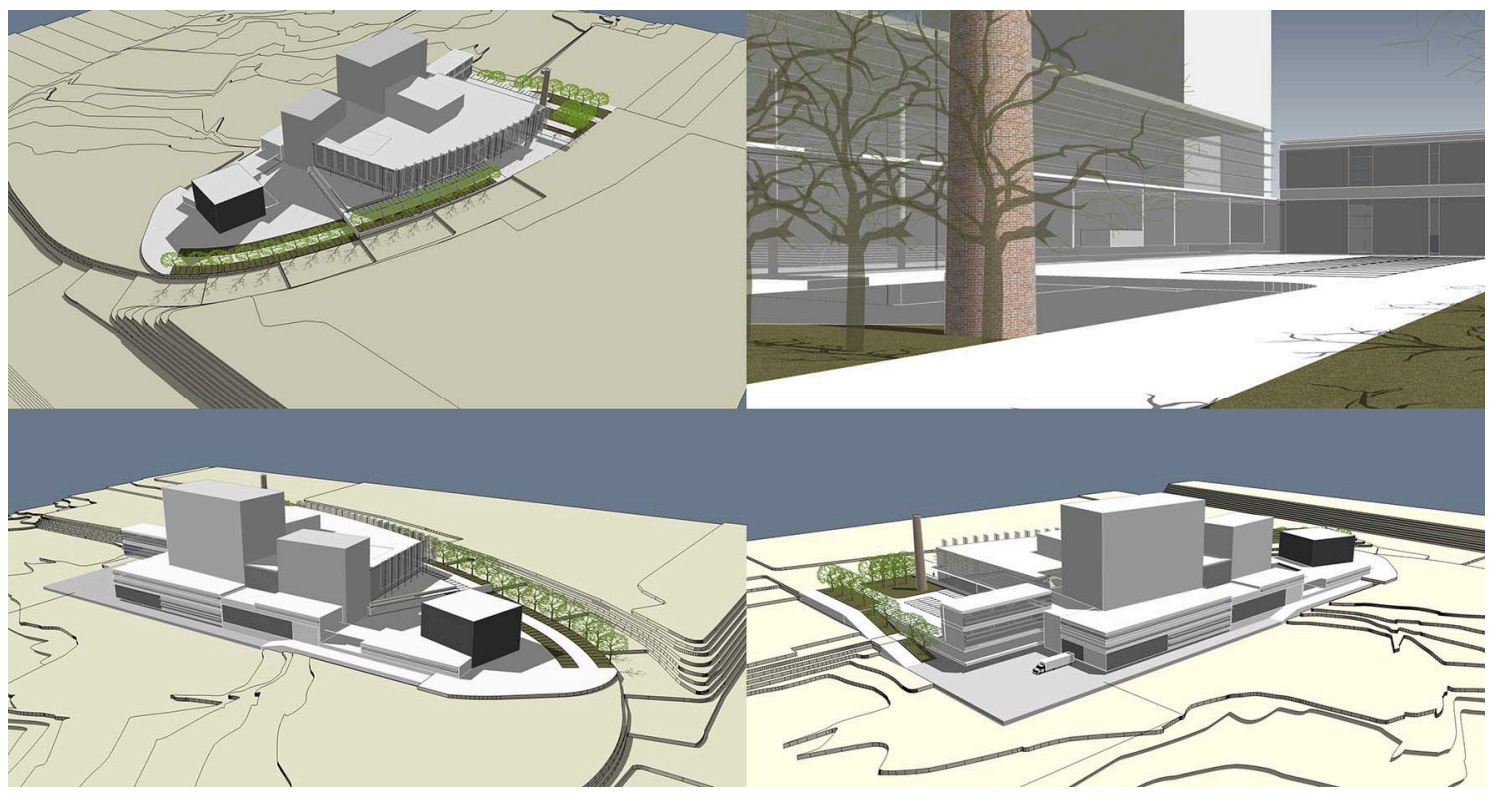

Fonte: Acervo do autor.

No desenho final da proposta para o teatro existiam dois níveis básicos. O platô natural na cota 556 foi reservado para as entradas das salas 2 e 3 (black box), que tinham bilheterias e estacionamento próprios e próximos. 0 estacionamento descoberto, linear, seria densamente arborizado para ajudar a sombrear o sol poente e permitir ver a cidade. O platô na cota 555 foi reservado às Áreas Técnicas. Formava-se por leve corte e simples raspagem do terreno natural e seria uma solução de baixo custo para o grande estacionamento coberto da Sala 1 (Figura 8).

\section{CONSIDERAÇÕES FINAIS}

Conforme indicado por Guedes, a "invenção da forma precisa" emergia:

- do conhecimento e domínio do terreno; 
- do conhecimento e domínio do programa (desejo do cliente)

- análise gráfica;

- do trabalho de organização dos sistemas de espaços no terreno - análise gráfica;

- da construção perfeita (GUEDES, 2007, prancha 1).

Na realização da proposta para o Teatro de Londrina, outras estratégias (como descritas acima por Guedes) desenvolveram-se simultaneamente, e não de maneira sequencial ou linear. A estratégia projetual com uso de Diagramas Lineares aqui apresentada, é considerada como apenas uma das etapas do processo de projeto, aplicado por Guedes. 
Figura 8: Proposta final para implantação (legendas e cores pelo autor).

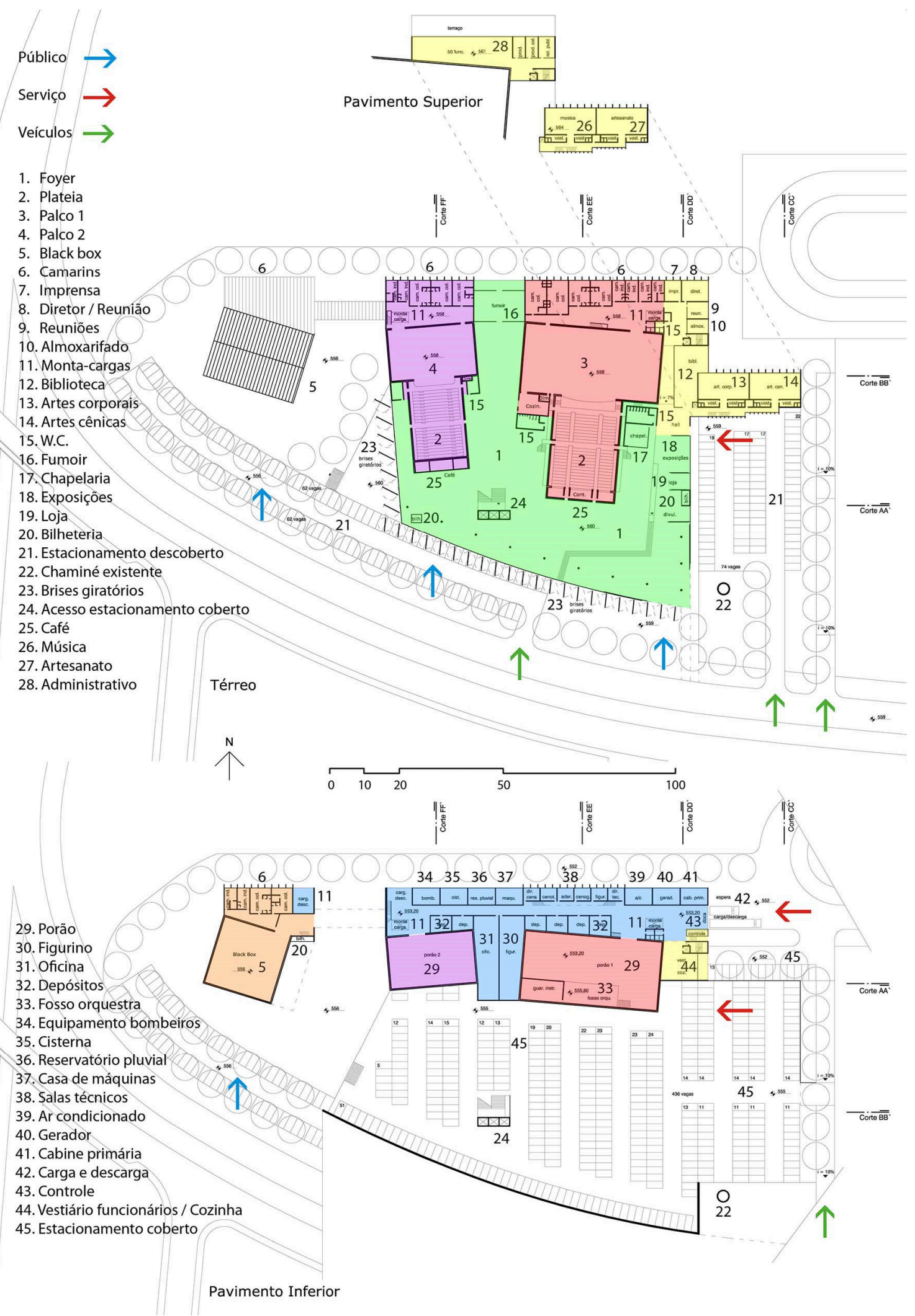

Fonte: Acervo do autor. 
Para a transposição dos Subsistemas de espaços em plantas e cortes, cada setor foi profundamente estudado como um componente independente dos demais. Por exemplo: as Salas 1, 2 e 3, depois de delimitados seus perímetros, foram sendo projetadas conforme as especificidades de cada uma, inicialmente de maneira independente de sua relação com o conjunto total. Posteriormente, para a construção dos volumes e sua articulação no terreno, realizou-se uma reorganização do conjunto conforme a disposição dos setores em Subsistemas de espaços afins.

\section{Figura 9: Montagem fotográfica com maquete eletrônica da volumetria final.}

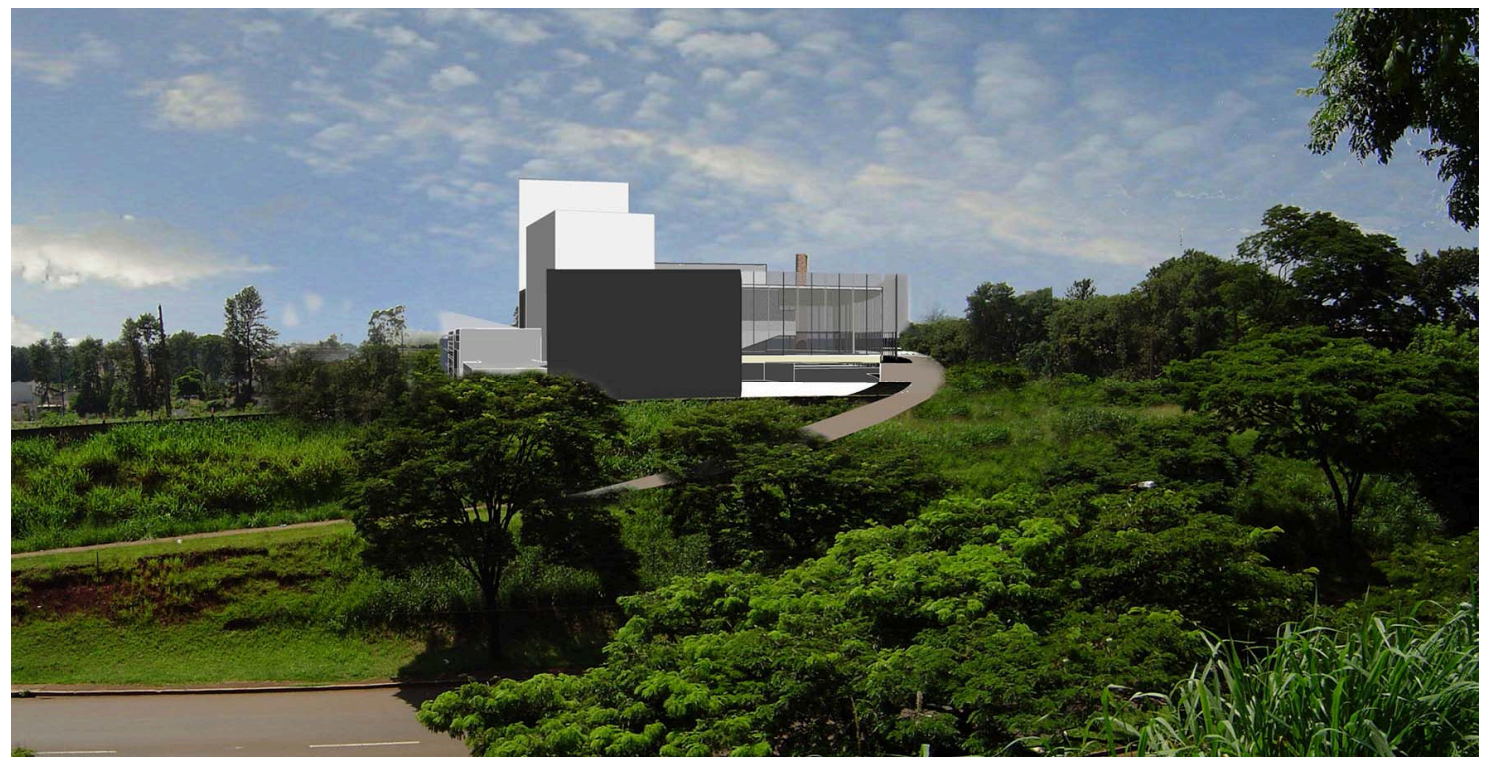

Fonte: Acervo do autor.

Avaliando essa estratégia projetual, percebe-se que uma de suas qualidades consiste em esclarecer a organização e a relação entre os espaços solicitados, no caso de programas de necessidades extensos e complexos. Na proposta para o Teatro de Londrina, por meio de um estudo profundo de arranjos e rearranjos que se relacionavam entre si, gradativamente foram sendo configuradas algumas atitudes projetuais, assim como o nascimento da forma (Figura 9).

\section{REFERÊNCIAS}

CALDANA JÚNIOR, V. L. Projeto de Arquitetura: Caminhos. 2005. Tese (Doutorado em Arquitetura e Urbanismo) - Faculdade de Arquitetura e Urbanismo da Universidade de São Paulo, São Paulo.

CONCURSO PÚBLICO NACIONAL DE ANTEPROJETOS DE ARQUITETURA PARA O TEATRO MUNICIPAL DE LONDRINA. Bases do Concurso. Londrina: 2006.

FOQUÉ, R. Building Knowledge in Architecture. Brussels: Antwerp University, 2010.

GUEDES, J. Memorial Descritivo do projeto para o Teatro de Londrina. São Paulo, 2007. 


\section{NOTAS}

1. A equipe formada por Guedes para esse concurso foi composta pelos arquitetos(as) Cristina Amaral, Carlos Amaral Jr., Ana Maria Coelho, Paula Katakura, Isis Roverso, Rafael Schimidt, Lucas Bond Schwartsburd, Kaled Goubar (Métodos Construtivos), Ataíde Xavier (Revestimentos Metálicos) e Francisco Guedes (Física da Arquitetura/Infraestrutura).

2. Guedes já havia realizado anteriormente uma proposta para o Teatro Municipal de Londrina, em 1993. 